\title{
Adsorção e lixiviação de boro em Latossolo Vermelho-Amarelo
}

\author{
Ciro Antonio Rosolem ${ }^{(1)}$ e Thaís Bíscaro(1)
} (1)Universidade Estadual Paulista, Fac. de Ciências Agronômicas, Dep. de Produção Vegetal, Caixa Postal 237, CEP $18603-970$ Botucatu, SP.
E-mail: rosolem@fca.unesp.br, tbiscaro@fca.unesp.br

\begin{abstract}
Resumo - O objetivo deste trabalho foi avaliar a adsorção e a lixiviação do boro em Latossolo Vermelho-Amarelo distrófico, cultivado com soja, em conseqüência das doses de boro e da calagem. Foram analisadas amostras de um solo do Estado do Mato Grosso, cultivado com soja durante três anos, com doses de 0, 1,5, 3, 4,5, 6, 7,5 e $9 \mathrm{Mg} \mathrm{ha}^{-1}$ de calcário, e $0,1,3,5,7$ e $10 \mathrm{~kg} \mathrm{ha}^{-1}$ de boro, aplicados no primeiro ano de cultivo. Foram determinadas isotermas de adsorção de boro em função da calagem e do tempo de cultivo, assim como a lixiviação em função da calagem e da adubação boratada. No caso da calagem, mesmo com doses relativamente altas de calcário, a adsorção de boro pelo solo é muito alta apenas no ano de aplicação do corretivo, e diminui significativamente com o tempo. No entanto, a lixiviação de boro guarda estreita relação com o teor do nutriente no solo e com a dose do nutriente que é aplicada, mas é pouco influenciada pela calagem.
\end{abstract}

Termos para indexação: ácido bórico, adubação, calagem, micronutrientes.

\section{Boron adsorption and leaching in a Brazilian Oxisol}

\begin{abstract}
The objective of this work was to evaluate soil boron dynamics in a Typic Hapludox cropped with soybean for three years, as affected by boron rates and liming. Soil samples were taken during three years from a field experiment with lime rates of $0,1.5,3,4.5,6,7.5$ and $9 \mathrm{Mg} \mathrm{ha}^{-1}$ and boron rates of $0,1,3,5,7$ and $10 \mathrm{~kg} \mathrm{ha}^{-1}$. Boron adsorption isotherms as affected by liming and time under cropping were determined. Boron leaching, as affected by boron fertilization and liming was also evaluated. When lime was applied, even at high rates, soil boron adsorption was very high only in the first year, and decreased with time. Boron leaching, though not affected by liming, is strongly related to soil boron contents and boron fertilization.
\end{abstract}

Index terms: boric acid, fertilization, liming, micronutrients.

\section{Introdução}

O conhecimento da capacidade do solo em adsorver boro (B) tem importância tanto para a correção de uma eventual deficiência do nutriente quanto para a prevenção dos casos de toxicidade, mas a lixiviação deste nutriente também pode ser um importante componente da dinâmica do elemento no solo (Communar \& Keren, 2007). Cinco mecanismos têm sido propostos para explicar a adsorção de B: adsorção de íon borato, adsorção de ácido bórico, formação de complexos orgânicos, precipitação de boratos insolúveis com alumina e sílica, e entrada do B nas grades cristalinas dos minerais de argila (Hatcher et al., 1967). A quantidade de $\mathrm{B}$ que um solo pode adsorver depende da concentração da solução em equilíbrio, do tempo de contato e da textura, $\mathrm{pH}$, do teor de matéria orgânica e da composição mineralógica do solo (Azevedo et al., 2001). Segundo Saltali et al. (2005), pH, os teores de argila e areia e a calagem são os fatores que mais influenciam a adsorção e lixiviação de B.
A adsorção de $\mathrm{B}$ aumenta até $\mathrm{pH} 9$, e decresce a partir daí (Goldberg et al., 2005), pois o ácido bórico é muito fraco, com $\mathrm{pK}=9,23$. Entretanto, quanto menor o teor de B no solo, menor o efeito do aumento do $\mathrm{pH}$ na adsorção do elemento (Goldberg, 1997). No Brasil, aumentos de $\mathrm{pH}$ de 4,2 a 5,6, em Latossolo Vermelho de textura média, causaram aumento significativo na quantidade de B adsorvido (Cruz et al., 1987).

Um aspecto importante a se considerar em estudos de adsorção é a grande afinidade existente entre o B e os hidróxidos de ferro e de alumínio (Hatcher et al., 1967; Sims \& Bingham, 1968a). Para um grupo de solos ácidos, o aumento na adsorção de $B$ foi altamente correlacionado ao alumínio trocável, precipitado pela adição de $\mathrm{CaCO}_{3}$, com efeito mais marcante do $\mathrm{Al}(\mathrm{OH})_{3}$ recém-precipitado (Souza et al., 1997; Prodromu, 2004).

A caulinita apresenta componentes (como hidróxidos de alumínio) com maior afinidade pelo B do que os hidróxidos de ferro (Sims \& Bingham, 1968b). Para solos 
brasileiros, ricos em caulinita e sesquióxidos de ferro e de alumínio, a adsorção de B constitui-se em fenômeno de grande importância. Deve-se esperar que a correção dos solos até $\mathrm{pH}$ em água de 6 , como é recomendada para um grande número de culturas, aumente a adsorção do B adicionado. Entretanto, a maior parte do B disponível no solo está ligada à fração orgânica, que o retém com grande força.

Parte do B que é adicionado ao solo como fertilizante permanece solúvel e pode ser lixiviado no perfil do solo (Silva et al., 1995). Também o B que não está, inicialmente, em solução, pode ser dessorvido e lixiviado (Communar \& Keren, 2006, 2007). A remoção do B adicionado ao solo é dependente da quantidade de água percolada e da textura do solo (Patil et al., 1997).

Solos de textura arenosa, pobres em matéria orgânica, tendem a apresentar baixa disponibilidade de B. Isto é especialmente importante em áreas muito chuvosas, onde o B pode ser lixiviado (Silva et al., 1995; Communar \& Keren, 2006). No entanto, os solos de texturas mais argilosas tendem a reter o B adicionado por períodos mais longos, o que também ocorre em solos com mais carbono orgânico e maior capacidade de troca catiônica (Chaudary \& Shukla, 2004).

Estudos de lixiviação têm mostrado que há menor remoção de B em águas de percolação de solos com calagem, em relação a solos sem calagem (Communar \& Keren, 2006).

A deficiência de B pode ser resultado de lixiviação excessiva, particularmente em solos arenosos, ou de excesso de calagem, que eleva a adsorção do nutriente ao solo.

Este trabalho teve como objetivo o estudo da adsorção e da lixiviação de boro, em um Latossolo VermelhoAmarelo distrófico.

\section{Material e Métodos}

Foram utilizadas amostras da camada superficial $(0-15 \mathrm{~cm})$ de um Latossolo Vermelho-Amarelo distrófico (Embrapa, 1999), argiloso (520 g kg-1 de argila, $100 \mathrm{~g} \mathrm{~kg}^{-1}$ de silte e $380 \mathrm{~g} \mathrm{~kg}^{-1}$ de areia), provenientes de um experimento com soja, conduzido durante três anos, em Campo Novo do Parecis, MT. O volume de chuvas da região é de aproximadamente $2.000 \mathrm{~mm}$ por ano, e a altitude é de aproximadamente $650 \mathrm{~m}$.

No campo, foram aplicados $0,1,3,5,7$ e $10 \mathrm{~kg} \mathrm{ha}^{-1}$ de $\mathrm{B}$ e $1,5,3,4,5,6,7,5$ e $9 \mathrm{Mg} \mathrm{ha}^{-1}$ de calcário. $\mathrm{O}$ sistema de cultivo foi o convencional e a calagem foi efetuada no primeiro ano agrícola, a lanço, e incorporada com grade até a profundidade de $20 \mathrm{~cm}$. O B foi aplicado a lanço, na forma de ulexita, e incorporado com grade antes da semeadura da soja, no primeiro ano.

O experimento de campo foi instalado em esquema fatorial 6x6 (seis doses de B e seis de calcário), com quatro repetições, em blocos ao acaso.

O estudo de adsorção e lixiviação de B foi realizado em laboratório. Para o estudo de adsorção de $\mathrm{B}$, foram utilizadas amostras de terra do tratamento sem $\mathrm{B}$, ou seja, quatro repetições das parcelas sem B e com calcário, de cada um dos três anos. Foi empregado o método de Osazaki \& Chao (1968), com modificação das concentrações de B para a faixa de 0 a $16 \mu \mathrm{g} \mathrm{mL}^{-1}$ (Alleoni \& Camargo, 2000).

Amostras de $4 \mathrm{~g}$ de terra foram colocadas em tubos de polietileno e acrescidas de $20 \mathrm{~mL}$ de solução de $\mathrm{CaCl}_{2}$ a $0,01 \mathrm{~mol} \mathrm{~L}^{-1}$, que continha $0,1,2,4,8$ e $16 \mu \mathrm{g} \mathrm{mL}^{-1} \mathrm{de}$ $\mathrm{B}$ na forma de ácido bórico. Os tubos foram mantidos em agitação lenta, por 24 horas, em agitador vertical. Em seguida, a suspensão foi centrifugada por $15 \mathrm{~min}$ a $2.000 \mathrm{rpm}$ (Shumway \& Jones, 1972), foi filtrada, e uma alíquota de $10 \mathrm{~mL}$ do sobrenadante foi tomada para a determinação do $\mathrm{B}$, por meio de indução de plasma. A quantidade de $\mathrm{B}$ adsorvido foi obtida pela diferença entre a concentração de B na solução inicial e o B remanescente na solução de equilíbrio, após a agitação e centrifugação. Os testes foram conduzidos com quatro repetições. Com os resultados do B adsorvido, foi obtida a curva de adsorção com a isoterma de Langmuir: $\mathrm{x} / \mathrm{m}=\mathrm{KCb} /(1+\mathrm{KC})$, em que $\mathrm{x} / \mathrm{m}$ é a massa de adsorvato por unidade de massa do adsorvente; $\mathrm{K}$ é a constante relacionada à energia de ligação adsorvatoadsorvente; $C$ é a concentração de equilíbrio do adsorvato; e b é a quantidade máxima de adsorvato que pode ser adsorvido pelo solo.

$\mathrm{O}$ ensaio de lixiviação de $\mathrm{B}$ foi realizado em colunas de PVC, com 2 polegadas de diâmetro, preenchidas com amostras de solo até a altura de $15 \mathrm{~cm}$. A base da coluna foi fechada com um círculo de papel filtro de filtragem lenta, fixado com tela anti-ofídica, presa com fita adesiva, de maneira que a solução saísse filtrada e límpida. As colunas foram seccionadas em três. Na remontagem das colunas, foi fixada uma fita adesiva nas emendas, de modo que ficasse de 0,5 a $1 \mathrm{~cm}$ dentro da terra, para evitar percolação preferencial pelas paredes do tubo. A quantidade de terra adicionada foi suficiente para proporcionar densidade global de $1,15 \mathrm{Mg} \mathrm{m}^{-3}$. Sobre a terra da coluna, foi colocado outro círculo de papel filtro. 
As amostras de solo provenientes dos tratamentos do experimento com calcário, em campo, foram combinadas para dar origem a novos tratamentos: calagem 1 - mistura das amostras com calagem de 1,5, 3 e 4,5 $\mathrm{Mg} \mathrm{ha}^{-1}$; e calagem 2 - mistura das amostras com calagem de 6, 7,5 e $9 \mathrm{Mg} \mathrm{ha}^{-1}$. Do experimento em campo, com doses de $\mathrm{B}$, foram utilizadas amostras de solo provenientes de apenas três dos seis tratamentos com B: $0 \mathrm{~kg} \mathrm{ha}^{-1}, 5 \mathrm{~kg} \mathrm{ha}^{-1}$ e $10 \mathrm{~kg} \mathrm{ha}^{-1}$. Em cada um desses novos tratamentos, foram aplicados, ou não, sobre a superfície das colunas, o correspondente a $5 \mathrm{~kg} \mathrm{ha}^{-1}$ de B, na forma de ácido bórico, a fim de se simular uma nova adubação boratada. O cálculo da quantidade de adubo aplicado nessa adubação simulada foi realizado em função da área superficial do vaso. A quantidade necessária para a dose de $5 \mathrm{~kg} \mathrm{ha}^{-1}$ de B foi diluída em $1 \mathrm{~mL}$ de água destilada, aplicada sobre o solo gota a gota, sem revolvimento. Decorridas duas horas da aplicação do B, as colunas foram submetidas a aplicações de água correspondentes a uma, duas, três e quatro vezes o volume total de poros determinado em cada coluna (Embrapa, 1997). A água foi aplicada por meio de uma bureta regulada, para fornecer água de modo que não houvesse acúmulo aparente na superfície do papel filtro. As soluções recolhidas nas bases das colunas, após a passagem da água, foram acondicionadas em recipientes de plástico e, posteriormente, analisadas por espectroscopia de indução de plasma.

$\mathrm{Na}$ análise de variância, foi considerado um esquema em fatorial $2 \times 3 \times 2$, ou seja, dois níveis de calagem, três doses de B com e sem adubação boratada de cobertura, com quatro repetições, em delineamento inteiramente casualizado. Foram ajustadas equações de regressão aos resultados obtidos, tendo-se escolhido as curvas de maior significância e melhor ajuste.

\section{Resultados e Discussão}

A adsorção de B no solo foi decrescente com o passar do tempo, tendo passado de resposta linear, no primeiro ano, para quadrática no segundo e terceiro anos, quando as curvas tenderam a um certo patamar (Figura 1). Da mesma forma, o efeito da calagem foi cada vez menos pronunciado com o passar do tempo, com diminuições da ordem de $72 \%$ nos valores de adsorção. Isso era esperado, uma vez que géis frescos de hidróxido de alumínio recém-precipitados adsorvem grandes quantidades de B, mas sua capacidade de adsorção diminui com o aumento da idade dos géis (Prodromu, 2004), efeito também observado por Souza et al. (1997). A proporção de adsorção relativamente menor,
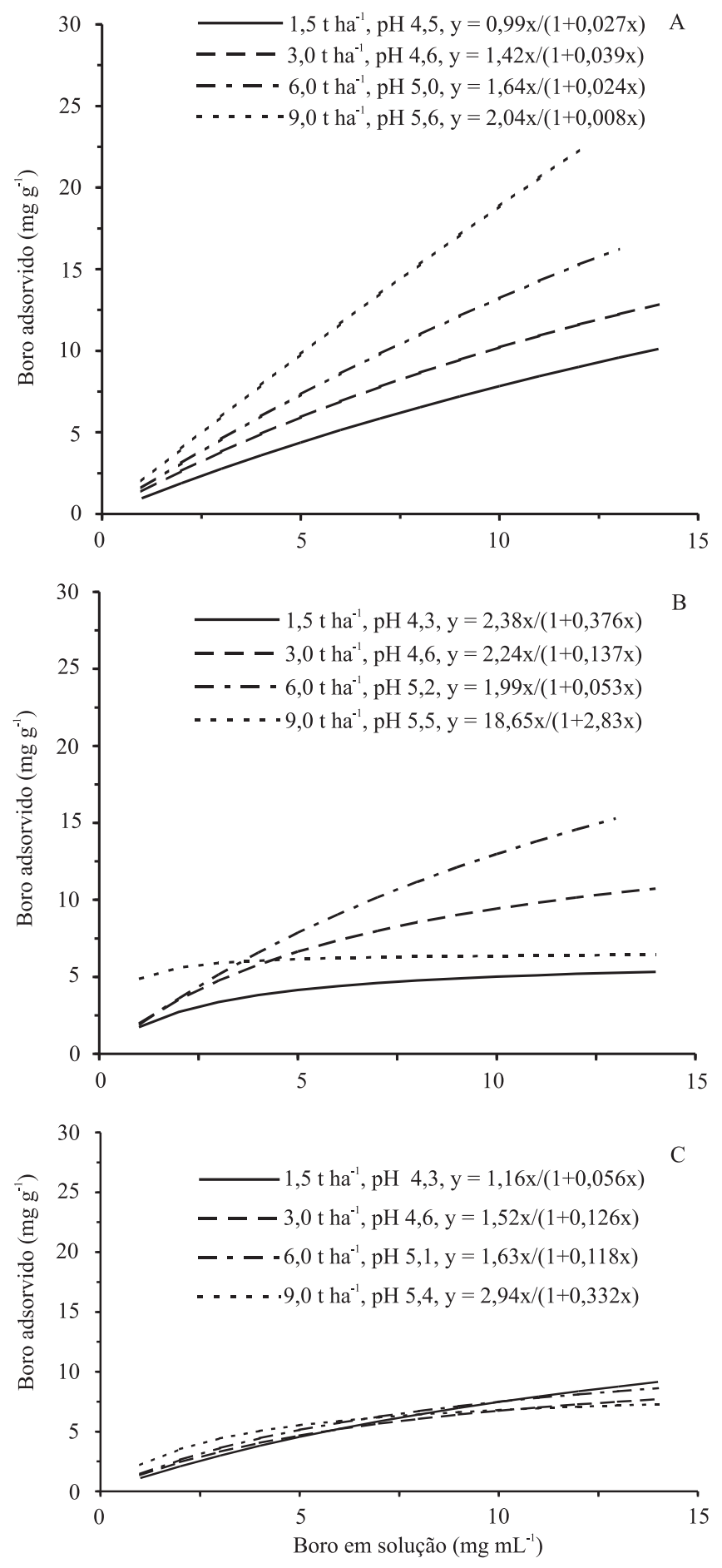

Figura 1. Isotermas de adsorção de boro no solo (Langmuir), em conseqüência da calagem no primeiro (A), segundo (B) e terceiro (C) anos do experimento. 
observada com as soluções mais concentradas, evidenciada pelas curvas de adsorção quadráticas, também foi observada em outros solos (Goldberg et al., 1997; Azevedo, 2001), tendo sido atribuída à falta de saturação da superfície adsorvente em sistemas heterogêneos.

A mudança do comportamento da adsorção de B com o tempo (Figura 1) pode estar associada, também, ao tempo de reação do cálcio com o solo, no decorrer dos anos, ou pode, ainda, estar associada à capacidade de adsorção ao $\mathrm{CaCO}_{3}$ presente no solo (Alleoni \& Camargo, 2000). No primeiro ano, com grande quantidade de $\mathrm{CaCO}_{3}$ presente, uma maior quantidade de $\mathrm{B}$ pode ser adsorvida.

A adsorção de B ocorre até determinado ponto crítico, a partir do qual a adsorção é baixa (Azevedo, 2001). $\mathrm{A}$ adição de $\mathrm{B}$, a partir deste ponto, somente terá como conseqüência maior perda do nutriente por lixiviação.

Considerando-se os resultados do presente experimento, pode-se inferir que, mesmo no caso de calagem com doses relativamente altas de calcário, a adsorção de B pelo solo somente é importante no ano em que foi realizada a calagem, de modo que, com o tempo, maior quantidade de B fica na solução do solo, em condições de ser prontamente absorvido pelas plantas ou mesmo ser perdido por lixiviação.

A adsorção máxima de $\mathrm{B}$, estimada pela isoterma de Langmuir, foi muito alta no primeiro ano do experimento (Figura 2). Com o baixo teor de B do solo, no presente experimento, não se esperava adsorção muito alta, uma vez que quanto menor o teor de B no solo, menor é o efeito do aumento do $\mathrm{pH}$ na adsorção do elemento (Goldberg, 1997). No entanto, Alleoni \& Camargo (2000) encontraram adsorções máximas de até $15,8 \mathrm{mg} \mathrm{g}^{-1}$ em solos do Estado de São Paulo, para o solo mais argiloso, e existem relatos, na literatura, de adsorção máxima mais alta do que essas, que podem chegar a valores da ordem de $200 \mathrm{mg} \mathrm{kg}^{-1}$ (Goldberg, 1997).

A grande adsorção máxima verificada com as maiores doses de calcário, principalmente no primeiro ano, pode ser entendida levando-se em consideração que ocorre importante adsorção de $\mathrm{B}$ nos hidróxidos de $\mathrm{Al}$ recentemente precipitados (Hatcher, 1967; Prodromu, 2004). Além disso, existe possibilidade de ligação do B com o carbonato, de precipitação de borato de cálcio, de substituição do carbono por $\mathrm{B}$ no $\mathrm{CaCO}_{3}$ ou, ainda, de adsorção do $\mathrm{B}$ ao $\mathrm{CaCO}_{3}$ (Alleoni \& Camargo, 2000).

Quanto maior a quantidade de água infiltrada no solo, maior foi a quantidade de B lixiviada (Figuras 3 e 4). Mesmo quando não houve adição do fertilizante boratado, parte do B originalmente presente no solo foi lixiviada. Como se esperava, as quantidades lixiviadas foram maiores (Figura 3) nos tratamentos que já haviam recebido $\mathrm{B}$ anteriormente no campo e, portanto, apresentavam mais B disponível. Da mesma forma que o B é adsorvido aos colóides, pode ocorrer a dessorção do nutriente, e a taxa de dessorção é inversamente proporcional ao teor de argila e de matéria orgânica do solo (Zerrari et al., 2001). A taxa de dessorção é positivamente correlacionada à taxa de percolação de água no solo (Communar \& Keren, 2006, 2007).

Não foi observado efeito significativo da calagem na lixiviação de $\mathrm{B}$, embora estudos de lixiviação tenham mostrado que é comum haver menor remoção de B em águas de percolação de solos com calagem, em relação a solos sem calagem (Communar \& Keren, 2006). No presente trabalho, a falta de efeito da calagem na lixiviação certamente é uma conseqüência da diminuição da adsorção máxima com o tempo, observada para todos os níveis de correção do solo com calcário. Assim, no ano da calagem, a

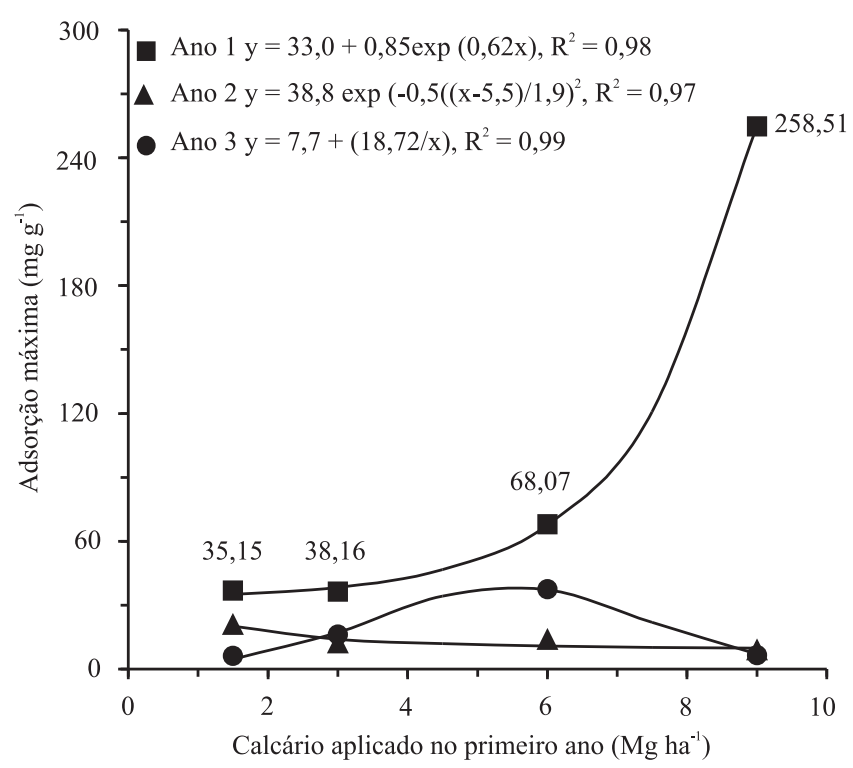

Figura 2. Adsorção máxima de boro no solo, determinada por isotermas de Langmuir. 
lixiviação pode ser menor, mas, com o tempo, deve aumentar.

Quando foi adicionado B ao solo, na dose de $5 \mathrm{~kg} \mathrm{ha}^{-1}$ na forma de ácido bórico em cobertura (Figura 4), as quantidades de B presentes na água percolada através das colunas de solo foram dez vezes maior do que as quantidades encontradas no tratamento sem adição de B.

Nos tratamentos com adubação de B em superfície, tanto nas doses mais baixas de calagem (média de 3,5 $\mathrm{Mg} \mathrm{ha}^{-1}$ ) quanto nas mais elevadas (média de 7,5 $\mathrm{Mg} \mathrm{ha}^{-1}$ ), as amostras de solos que haviam sido adubados anteriormente, com 5 e $10 \mathrm{~kg} \mathrm{ha}^{-1}$ de B, tiveram a quantidade máxima de $\mathrm{B}$ perdida próxima a
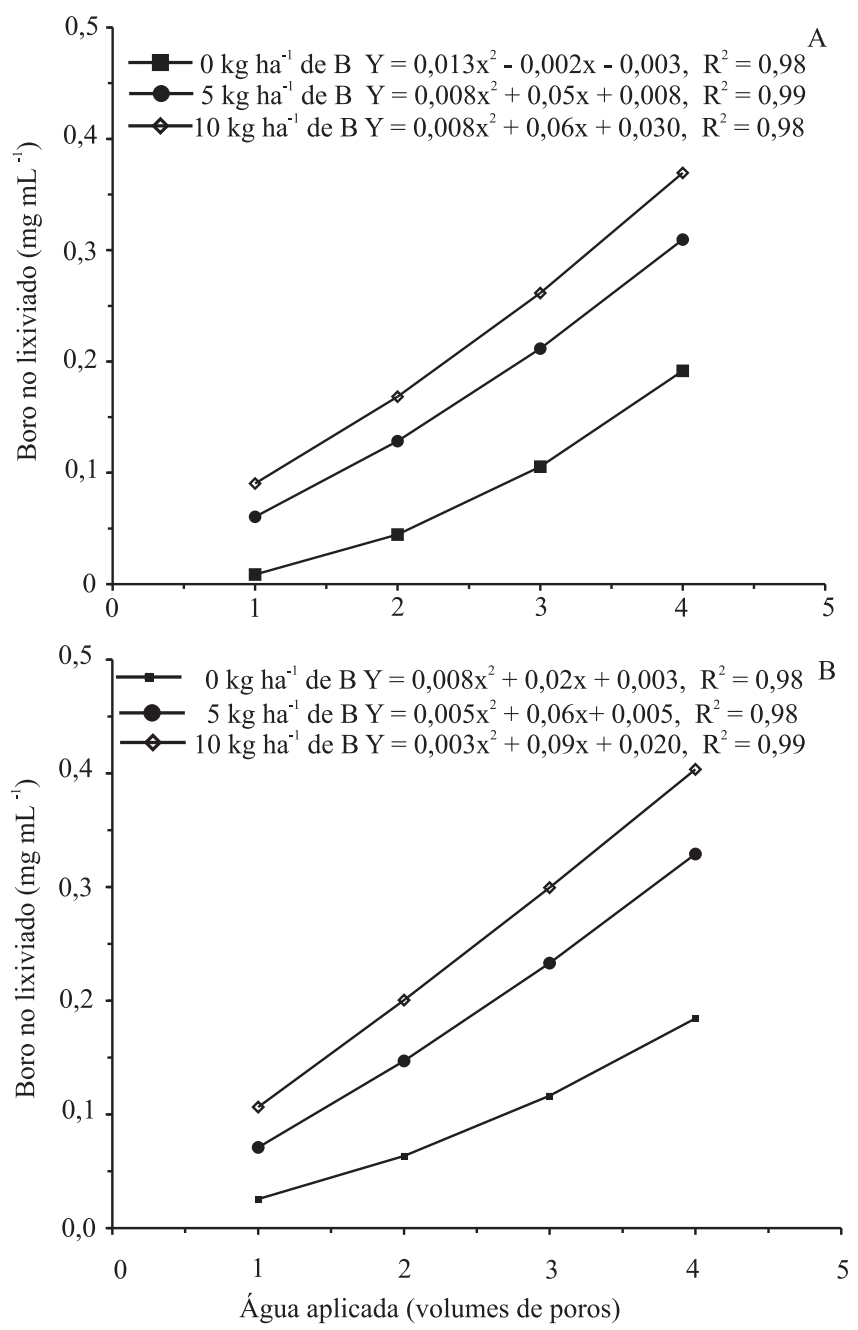

Figura 3. Boro determinado na solução lixiviada, em conseqüência do volume de água percolado, da adubação residual com boro e da aplicação média de 3 (A) e 7,5 $\mathrm{Mg} \mathrm{ha}^{-1}$ (B) de calcário, sem reaplicação de ácido bórico.
$6,1 \mu \mathrm{g} \mathrm{mL} \mathrm{m}^{-1}$. Esses resultados ajudam a explicar o fato de que, apesar de se utilizarem doses relativamente altas de B no Centro-Oeste, não é comum a constatação de sintomas de toxicidade, pois quando se adiciona $\mathrm{B}$ ao solo, grande parte desse elemento pode ser perdida por lixiviação. Resultados semelhantes foram obtidos na China por Wang et al. (1999), que demonstraram que, se por um lado a lixiviação de B leva à perda econômica, por outro lado, pode ser um fator de segurança quando se aplicam doses excessivas do nutriente. No entanto, a lixiviação de B, mesmo sem causar perdas à produção agrícola, é um fator de risco para o lençol freático, que pode ser contaminado.
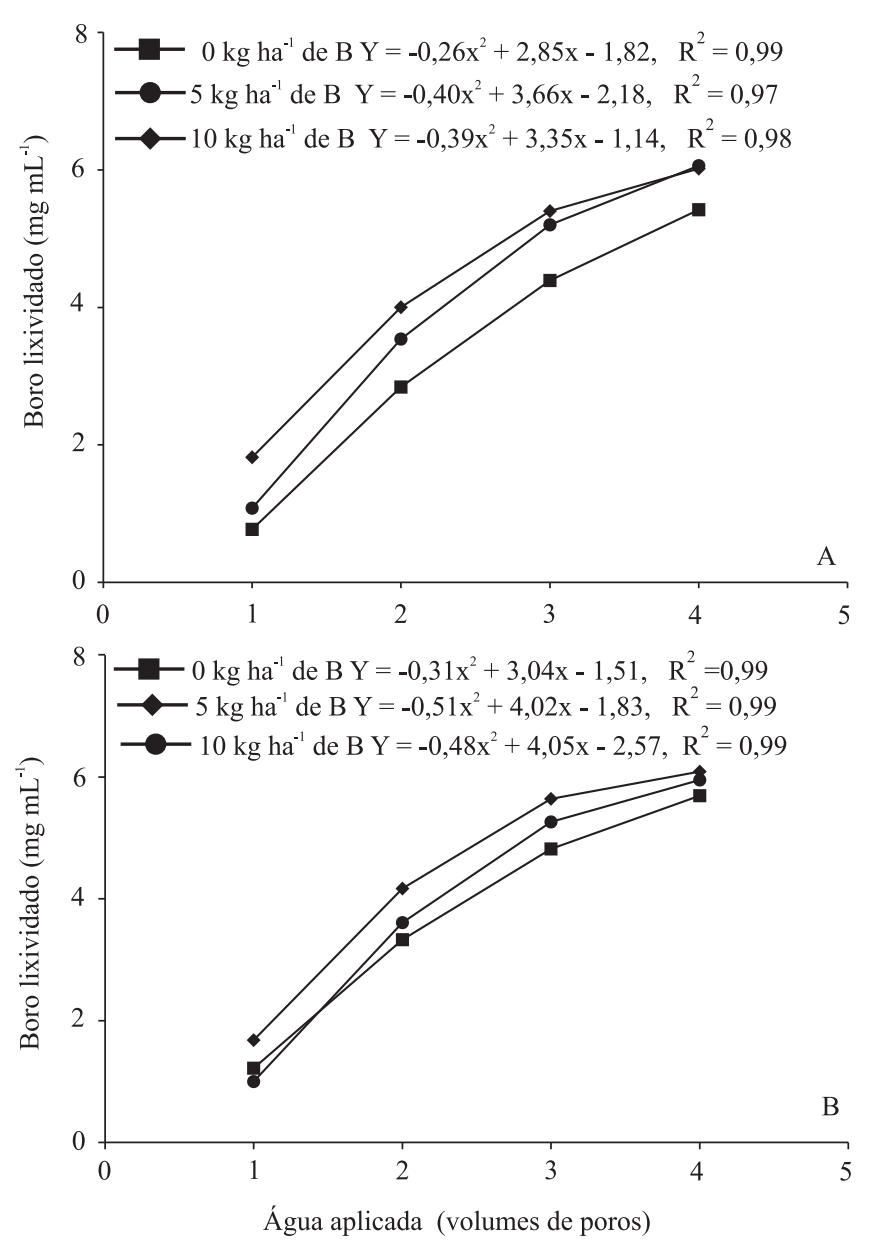

Figura 4. Boro determinado na solução lixiviada, em conseqüência do volume de água percolado, da adubação residual com boro e da aplicação média de 3 (A) e 7,5 $\mathrm{Mg} \mathrm{ha}^{-1}$ (B) de calcário, com reaplicação, em superfície, de $5 \mathrm{~kg} \mathrm{ha}^{-1}$ de boro na forma de ácido bórico. 


\section{Conclusões}

1. A adsorção de boro pelo solo corrigido com calcário é muito alta no ano de realização da calagem, e diminui com o tempo.

2. A lixiviação de boro guarda estreita relação com os teores de nutrientes no solo e com a dose que é aplicada, mas é pouco influenciada pela calagem.

\section{Referências}

ALLEONI, L.R.F.; CAMARGO, A.O. Boron adsorption in soils from the State of São Paulo, Brazil. Pesquisa Agropecuária Brasileira, v.35, p.413-421, 2000.

AZEVEDO, R.A.; FAQUIN, V.; FERNANDES, L.R. Adsorção de boro em solos de várzea do Sul de Minas Gerais. Pesquisa Agropecuária Brasileira, v.36, p.957-964, 2001.

CHAUDHARY, D.R.; SHUKLA, L.M. Boron adsorption and desorption in arid soils of India. Agrochimica, v.48, p.141-152, 2004.

COMMUNAR, G.; KEREN, R. Effect of transient irrigation on boron transport in soils. Soil Science Society of America Journal, v.71, p.306-313, 2007.

COMMUNAR, G.; KEREN, R. Rate-limited boron transport in soils: the effect of soil texture and solution $\mathrm{pH}$. Soil Science Society of America Journal, v.70, p.882-892, 2006.

CRUZ, M.C.P.; NAKAMURA, A.M.; FERREIRA, M.E. Adsorção de boro pelo solo: efeito da concentração e o pH. Pesquisa Agropecuária Brasileira, v.22, p.621-626, 1987.

EMBRAPA. Centro Nacional de Pesquisa de Solos. Sistema brasileiro de classificação de solos. Brasília: Embrapa-SPI; Rio de Janeiro: Embrapa-CNPS, 1999. 412p.

EMBRAPA. Centro Nacional de Pesquisa do Solo. Manual de métodos de análises de solo. Rio de Janeiro: Embrapa-CNPS, 1997. $212 \mathrm{p}$.

GOLDBERG, S. Reactions of boron with soils. Plant Soil, v.193, p.35-48, 1997.

GOLDBERG, S.; CORWIN, D.L.; AHOUSE, P.J.; SUAREZ, D.L. Prediction of boron adsorption by field samples of diverse textures. Soil Science Society of America Jounal, v.69, p. 1379-1388, 2005.
HATCHER, J.T.; BOWER, C.A.; CLARCK, M. Adsorption of boron by soils as influenced by hidroxy aluminum and surface area. Soil Science, v.104, p.422-426, 1967.

OKAZAKI, E.; CHAO, T.T. Boron adsorption and desorption by some Hawaiian soils. Soil Science, v.105, p.255-259, 1968.

PATIL, S.G.; SETKAR, S.; HEBBARA, M. Relationship between water table depth, soil boron and sunflower genotypic response on a saline soil. In: DELL, B.; BROWN, P.H.; BELL, R.W. (Ed.). Boron in soils and plants. Dordrecht: Kluwer Academic Publishers, 1997. p.261-264.

PRODROMU, K.P. Boron adsorption by amorphous $\mathrm{Al}(\mathrm{OH})_{3}$ in the presence of low molecular weight organic acids. Agrochimica, v.48, p.172-176, 2004.

SALTALI, K.; BILGILI, A.V.; TARAKCIOGLU, C.; DURAK, A. Boron adsorption in soils with different characteristics. Asian Journal of Chemistry, v.17, p.2487-2494, 2005.

SHUMWAY, J.S.; JONES, J.P. Boron adsorption isotherm: a method to estimate boron fertilizer requirement. Communications in Soil Science and Plant Analysis, v.3, p.477-485, 1972.

SILVA, N.M.; CARVALHO, L.H.; KONDO, J.I.; BATAGLIA, O.C.; ABREU, C.A. Dez anos de sucessivas adubações com boro no algodoeiro. Bragantia, v.54, p.177-185, 1995.

SIMS, J.R.; BINGHAM, F.T. Retention of boron by layer silicates, sesquioxides and soil materials: II. Sesquioxides. Soil Science Society of America Proceedings, v.32, p.364-369, 1968a.

SIMS, J.R.; BINGHAM, F.T. Retention of boron by layer silicates, sesquioxides and soil materials: III. Iron and aluminum-coated layer silicates and soil materials. Soil Science Society of America Proceedings, v.32, p.369-373, 1968b.

SOUZA, E.C.; ROSOLEM, C.A.; COUTINHO, E.L.M. Sunflower response to boron as affected by liming. In: DELL, B.; BROWN, P.H.; BELL, R.W. (Ed.). Boron in soils and plants. Dordrecht: Kluwer Academic Publishers, 1997. p.23-27.

WANG, K.; YANG, Y.; BELL, R.W.; XUE, J.M.; YE, Z.Q.; WEI, Y.Z. Low risks of toxicity from boron fertilizer in oilseed rape-rice rotations in Southeast China. Nutrient Cycling in Agroecosystems, v.54, p.189-197, 1999.

ZERRARI, N.; MAOUSTAOUI, D.; VERLOO, M. Boron adsorption and desorption in soils and influence of fertilization intensiy. Agrochimica, v.45, p.207-217, 2001.

Recebido em 14 de maio de 2007 e aprovado em 10 de setembro de 2007 